\title{
Composite Epoxy-Graphite Materials and Their Electrochemical Application ${ }^{\dagger}$
}

\author{
Abel I Balbin 1,* \\ 1 Applied Analysis and Electroanalysis Group (GAEA), Department of Analytical Chemistry, University of Havana, Cuba; \\ ibrahim@fq.uh.cu (A.I.B.); \\ * Correspondence: ibrahim@fq.uh.cu; \\ $\dagger$ Presented at Materials Chemistry and Physics (Materials Chemistry 2020) - International e-Conference
}

Received: 16.09.2020; Revised: 20.09.2020; Accepted: 24.09.2020; Published: 27.09.2020

\begin{abstract}
A great deal of attention has been given to the use of graphite in composite materials, taking advantage of their exceptional mechanical and electrical properties for developing electrochemical platforms and can also be easily modified, allowing the incorporation of different components. Various epoxy-graphite composites modified with benzoic acid, graphene oxide, and hydrotalcite were developed. The epoxy-graphite composites were characterized by cyclic voltammetry; electrochemical impedance spectroscopy, and field-emission scanning electron microscopy. The electrochemical behavior of the composites was analyzed from the reversibility of the $\mathrm{Fe}(\mathrm{CN})_{6}{ }^{3-} / \mathrm{Fe}(\mathrm{CN})_{6}{ }^{4-}$ as a redox probe by the dependency of peak potential, the anode current relationship, and cathodic current with scan rate. Besides the advantage of being prepared by a simple and not costly procedure, the hydrotalcite-modified graphite-epoxy composite indicating the possible application of electrode for ionic exchange of positive species and potential for electroanalytical purposes; and the epoxy-graphite composite electrodes modified whit benzoic acid and graphene oxide offer both the possibility of obtaining electrochemical response at low concentrations of free DNA base and single DNA, and the required binding groups on the electrode surface for covalent immobilization of specific oligonucleotides. From the study of the electrochemical properties of epoxy-graphite composites, it was possible to determine: Lapachol, nitrogenous bases, oligonucleotides, single strands of Calf thymus DNA, and proviral DNA of HIV-1 in the clinical sample.
\end{abstract}

Keywords: epoxy-graphite; composites; electrochemical.

(C) 2020 by the authors. This article is an open-access article distributed under the terms and conditions of the Creative Commons Attribution (CC BY) license (https://creativecommons.org/licenses/by/4.0/).

\section{Funding}

We thank CAPES-PRINT - 88887.468215/2019-00 for financial support.

\section{Acknowledgments}

The author is grateful to Prof. Hideko Yamanaka and the biosensor group of the Institute of Chemistry of Araraquara and to Prof. Ricardo Q. Aucélio of the Chemistry Department, Pontifícia of Universidade Católica do Rio de Janeiro (PUC-Rio), for their help in the development of the work presented here. 


\section{Conflicts of Interest}

The author declares that they have no known competing financial interests or personal relationships that could have appeared to influence the work reported in this paper. 